\title{
Experimental study of in-line tube bundle heat transfer in vertical foam flow
}

\author{
J. Gylys ${ }^{1}$, S. Sinkunas ${ }^{2}$, V. Giedraitis ${ }^{2} \&$ T. Zdankus ${ }^{1}$ \\ ${ }^{1}$ Energy Technology Institute, \\ Kaunas University of Technology, Lithuania \\ ${ }^{2}$ Department of Thermal and Nuclear Energy, \\ Kaunas University of Technology, Lithuania
}

\begin{abstract}
Foam has an especially large inter-phase contact surface which allows using it as a coolant. Characteristics of one type of foam - statically stable foam demonstrated its perfect availability for this purpose. Our previous investigations of heat transfer processes in statically stable foam flow showed that large heat transfer intensity may be reached at a small mass flow rate of the foam. Statically stable foam flow is the two-phase system that has number of peculiarities: drainage of liquid from foam, diffusive gas transfer and destruction of inter-bubble films. Those phenomena are closely linked with each other and make extremely complicated an application of analytic methods for the study of heat transfer in foam. Thus experimental method of investigation was selected in our work. Experimental investigation of the heat transfer process from the in-line tube bundle to the vertical statically stable foam flow was performed. Dependency of heat transfer intensity on flow parameters and on tube position in the bundle was determined. The results of the experimental investigation are presented in this paper.
\end{abstract}

Keywords: vertical foam flow, void fraction, heat transfer, experimental channel, in-line tube bundle.

\section{Introduction}

Foams are suitable for a lot of different purposes. It can be applied for heat and mass transfer performance as well, but usage of foam as coolant in heat exchangers or in foam apparatus depends on capability to "control" foam flow. 
Wide scientific researches of foam generation [1, 2], formed bubbles structure [1, 3], stability and disintegration [2, 4], foam flow hydrodynamics [3] and so on are necessary for its employment in mentioned cases. However, heat transfer process are investigated insufficiently especially in the regime of statically stable foam. Statically stable foam is such type of foams, which keeps its initial structure and bubbles' dimensions within broad limits of time intervals, from several seconds to days, even after termination of the foam generation. Our previous investigations showed the availability to use a statically stable foam for heat transfer. Heat transfer of different tube bundles to one-phase fluids was investigated enough, but practically there are not data of tube bundles heat transfer to foam flow. Heat transfer of alone cylindrical tube and of tube line to upward statically stable foam flow was investigated in our previous works [3]. The experimental series with staggered tube bundle in upward and downward foam flow followed as well [5-7]. It was determined dependence of heat transfer intensity on the following flow parameters: velocity, direction of foam flow, volumetric void fraction and liquid drainage from foam. Apart of that, influence of tube position in the bundle on heat transfer intensity was investigated also. Presently experimental investigation of heat transfer process from the in-line tube bundle to the vertical upward moving statically stable foam flow was performed. Results of investigations were generalized using relationships between Nusselt number and Reynolds number and volumetric void fraction of foam. The obtained generalized equation can be used for the designing of foam heat exchangers and calculating of heat transfer intensity of the in-line tube bundle.

\section{Experimental set-up}

The investigations were performed on the experimental set-up consisting of foam generator, vertical channel and bundle of the horizontal tubes, fig. 1. Cross section of the channel had square profile with a dimension of each side $140 \mathrm{~mm}$. Tubes of the bundle were located in five vertical lines with six tubes in each of them, fig. 2. Outside diameter of all tubes was $d=20 \mathrm{~mm}$. Spacing between rows of tubes was $s_{1}=30 \mathrm{~mm}$ and spacing between tubes in vertical row was $s_{2}=30 \mathrm{~mm}$ too. Volumetric void fraction and velocity of foam flow was controlled by the changing of the air and liquid rates. Experiments were performed within Reynolds number diapason for gas 190 $\div 440$ and foam volumetric void fraction $-0.996 \div 0.998$. Tube was heated electrically. An electric current value was measured by ammeter and voltage by voltmeter.

The temperature of foam flow was measured by two calibrated thermocouples: one in front of the bundle and one behind. The temperature of heated tube surface was measured by eight calibrated thermocouples. Six of them were placed around central part of heated tube and two of them were placed in both sides of the tube at $50 \mathrm{~mm}$ distance from the central part.

Water solution with detergents was used in experiments. Concentration of detergents was kept constant and it was equal $0.5 \%$. 

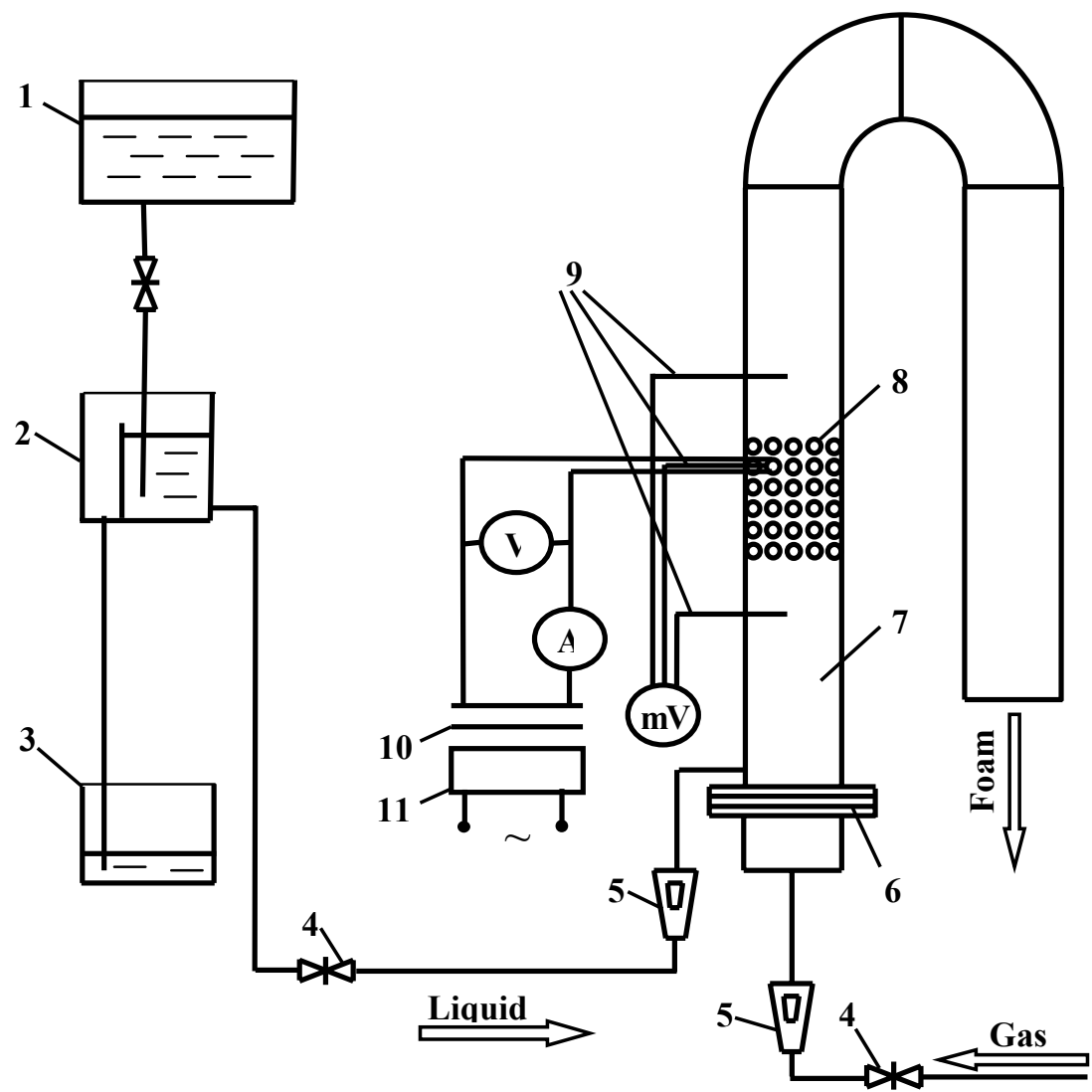

Figure 1: Experimental set-up scheme: 1-liquid reservoir; 2-liquid level control reservoir; 3-liquid receiver; 4-gas and liquid control valves; 5-flow meter; 6-foam generation riddle; 7-experimental channel; 8-tube bundle; 9-thermocouples; 10-transformer; 11-stabiliser.

The foam flow volumetric void fraction can be expressed by the eqn (1)

$$
\beta=\frac{G_{g}}{G_{g}+G_{l}} .
$$

The temperature of the heated tube surface and the foam flow, electric current and voltage were measured and recorded during the experiments. The preliminary investigations showed that hydraulic and thermal regime stabilizes completely within 5 minutes after the change of experiment conditions. Therefore measurements were started not earlier than 5 minutes after adjustment of foam flow parameters. After registration of electric current and voltage the heat flux density on the tube surface $q_{w}$ was calculated. After record of heated 
tube surface and foam flow temperatures, the difference of temperature $\overline{\Delta T}$ (between the mean temperatures of the foam flow $\bar{T}_{f}$ and tube surface $\bar{T}_{w}$ ) was calculated. The average heat transfer coefficient was calculated as

$$
\bar{\alpha}=\frac{q_{w}}{\overline{\Delta T}} .
$$

The Nusselt number was computed by formula

$$
\overline{N u}_{f}=\frac{\overline{\alpha d}}{\lambda_{f}} .
$$

where $\lambda_{f}$ is the thermal conductivity of the statically stable foam flow, $\mathrm{W} /(\mathrm{m} \cdot \mathrm{K})$, computed from the eqn (4)

$$
\lambda_{f}=\beta \lambda_{g}+(1-\beta) \lambda_{l} .
$$

The gas Reynolds number of foam flow was computed by formula

$$
\overline{\operatorname{Re}}_{g}=\frac{G_{g} d}{A v_{g}} .
$$

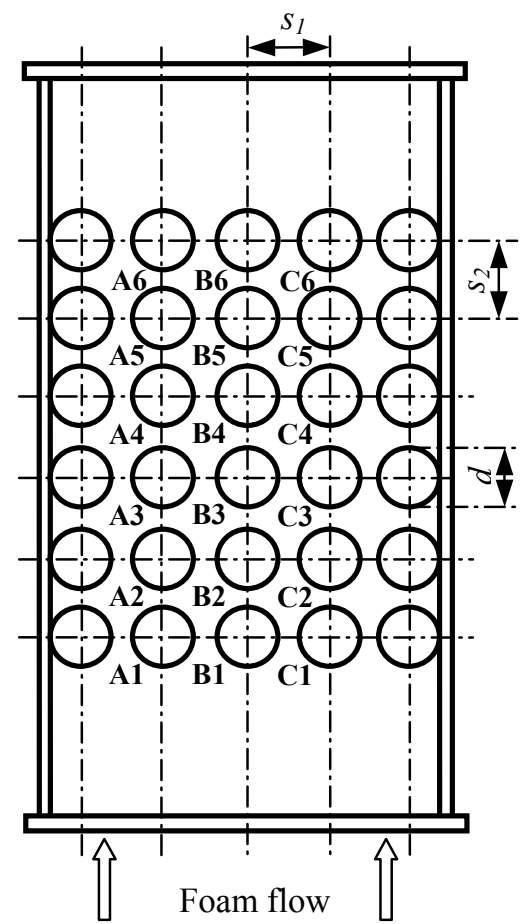

Figure 2: Tube bundle in vertical foam flow. 
All experiments and measurements were repeated in order to avoid measurement errors and to increase reliability of investigation results. The experimental uncertainties [8] in the range of test data variation: $\pm 8.0 \%$ for $\bar{\alpha}$, $\pm 8.1 \%$ for $\overline{N u}_{f}, \pm 2.2 \%$ for $\overline{R e}_{g}$.

\section{Results}

The experimental results showed that the heat transfer intensity of the in-line tube bundle for the foam flow is much higher than for the one-phase airflow under the same conditions (flow velocity). Data of heat transfer intensity as a function of $\overline{R e}_{g}$ for the first tube (B1) of the middle line and for comparison in one-phase airflow is shown in figure 3. With increasing of the gas Reynolds number for the foam flow $\overline{R e}_{g}$ within the limits $190 \div 440$, heat transfer intensity $\left(\overline{N u}_{f}\right)$ of the first tube (B1) increases by 2.5 times for the foam with volumetric void fraction $\beta=0.996$ and by 2.3 times for $\beta=0.997$, and by 1.9 times for $\beta=0.998$. So, the heat transfer intensity of the first tube (B1) to the wettest foam flow ( $\beta=0.996)$ depends on $\overline{R e}_{g}$ more than foam flow with volumetric void fraction $\beta=0.997$ and 0.998 .

There is (fig. 4) shown the comparison of heat transfer intensity of the first (B1) and the third tube (B3) in the middle line. The heat transfer of the third (B3) tube is worse than of the first-frontal (B1) tube for the whole interval of the gas Reynolds number.

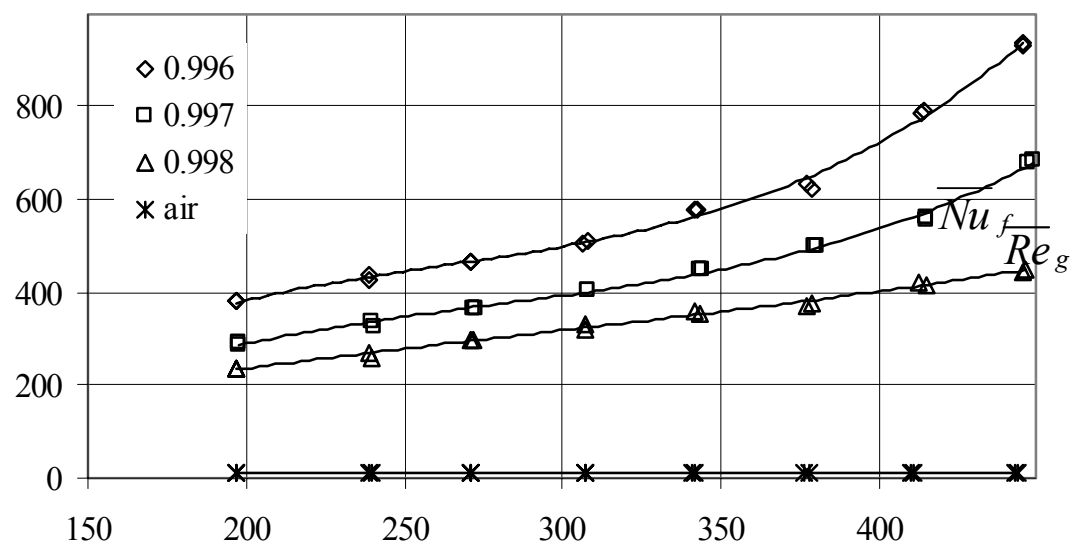

Figure 3: Heat transfer of the first tube (B1): $\beta=0.996,0.997$ and 0.998 , and in airflow. 


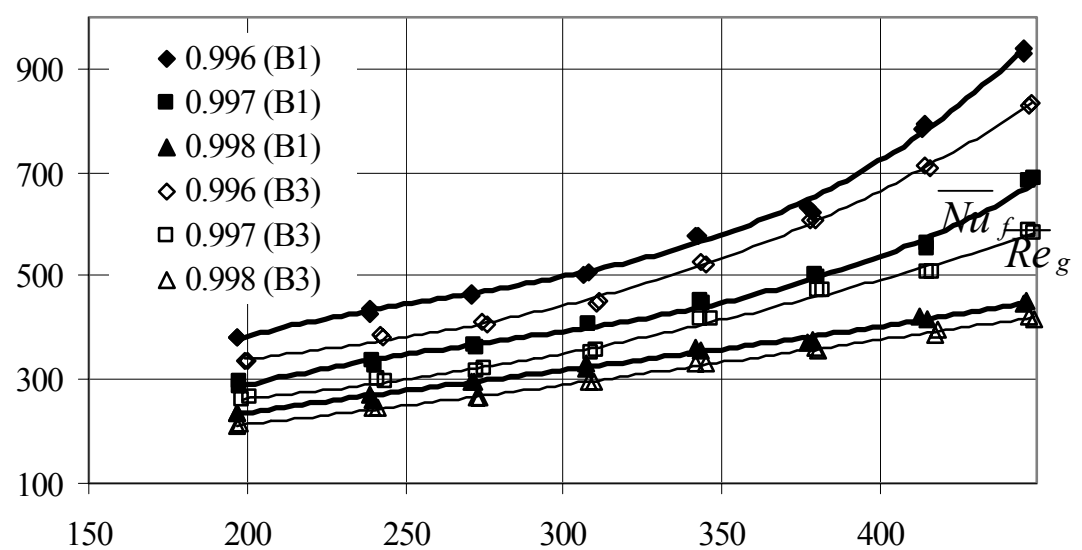

Figure 4: Comparison of heat transfer intensity of the first (B1) and the third tube (B3) in the middle line.

In one-phase flow case the heat transfer intensity of frontal tubes are equal to about $60 \%$ of the third tubes heat transfer intensity, heat transfer of the second tubes are equal to about $90 \%$ of the third tubes heat transfer intensity, and the heat transfer intensity of the fourth and furthered tubes in the in-line tube bundles are like of the third tubes [9]. Our experimental investigation shows that the heat transfer intensity of the third tube (B3) is equal to in average $90 \%$ of the first tube (B1) heat transfer intensity for the wettest and wetter foam flow $(\beta=0.996$ and 0.997$)$ and to in average $92 \%$ for the driest foam flow $(\beta=0.998)$.

The comparison of heat transfer intensity for the middle line at the volumetric void fraction $\beta=0.997$ is shown in figure 5 . The heat transfer of the first tube is better than that of the second tube, heat transfer of the second tube is better than that of the third tube and the heat transfer of the third tube is better than that of the fourth tube. The heat transfer intensity of fifth and sixth tubes is different from previously mentioned order. The heat transfer intensity of the fifth tube is better than that of the fourth tube and less than that of the third and the sixth tubes in whole interval of gas Reynolds number for foam flow. The heat transfer intensity of the sixth - the last tube is higher than that of the third tube when $\overline{R e}_{g}<330$ and less when $\overline{R e}_{g}$ increases from 330 to 440 .

This phenomenon can be explained by the fact that structure of foam flow changes while it passes the tube bundle. The large bubbles of foam are divided into smaller bubbles, some of foam bubbles collapse. So, the real void fraction and the intensity of the liquid drainage process are not the same along the experimental channel. 


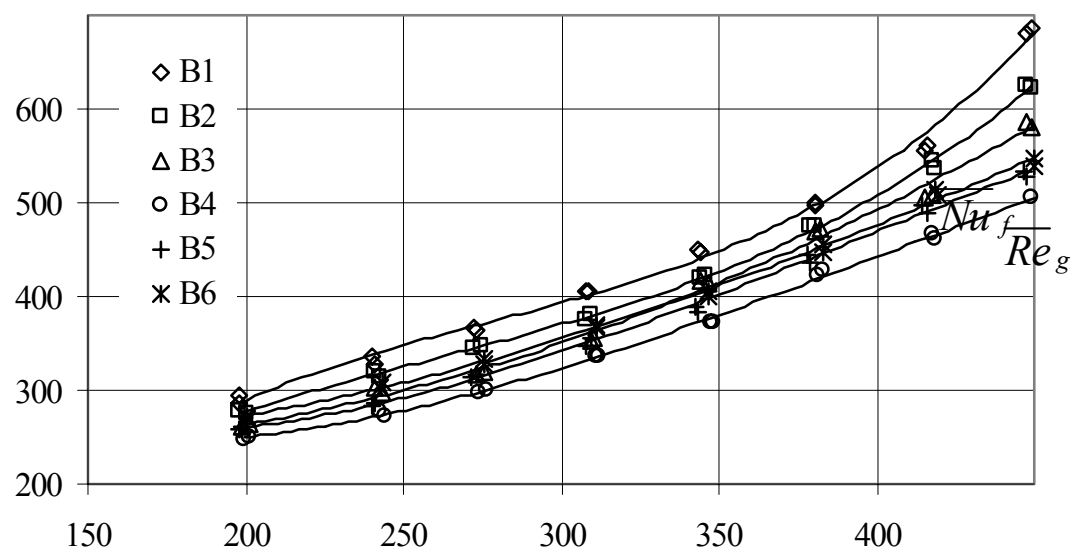

Figure 5: $\quad$ Heat transfer intensity of the tubes in the middle line, $\beta=0.997$.

Experimental results of the heat transfer of the in-line tube bundle to upward statically stable foam flow were summarised by criterion equations using the dependence between the Nusselt number and gas Reynolds $\overline{R e}_{g}$ number for the foam flow. This dependence within the interval $190<\overline{R e}_{g}<440$ for the in-line tube bundle in upward foam flow with the volumetric void fraction $\beta=0.996$, 0.997 , and 0.998 can be expressed as follows:

$$
\overline{N u}_{f}=c \beta^{n} \overline{\operatorname{Re}}_{g}^{m} .
$$

On average, for the entire middle line in the bank $c=6.64, n=305$, $m=-95(\beta-1.006)$ and on average, for the whole in-line tube bank $c=7.6, n=328$, $m=-95(\beta-1.006)$.

\section{Conclusions}

An experimental investigation of the heat transfer intensity was performed for inline tube bundle under the upward cross flow of the statically stable foam.

The experimental results showed that the heat transfer intensity of the in-line bundle tubes for the foam flow is from 20 to 80 times (dependent on tube position in the bundle) higher than for the one-phase airflow under the same conditions.

The experimental investigation showed that the heat transfer of the frontal tubes to upward foam flow is the best. It is different in comparison with one-phase fluid flow, case.

Exceptional case is the heat transfer of the last and the fifth tubes in the middle line of the tube bundle. The peculiarities of foam as two-phase system take place in this occasion. 
The experimental results were generalised by criterion equation, which can be used for the calculation and design of the statically stable foam heat exchangers.

\section{Nomenclature}

$A$ - cross section area of experimental channel, $\mathrm{m}^{2} ; c, m, n$ - coefficients; $d$ - outside diameter of tube, $\mathrm{m} ; G$ - volumetric flow rate, $\mathrm{m}^{3} / \mathrm{s} ; \overline{N u}-$ Nusselt number; $q$ - heat flux density, W/m² $\overline{R e}-$ Reynolds number; $\bar{T}-$ average temperature, $\mathrm{K} ; \bar{\alpha}-$ average coefficient of heat transfer, $\mathrm{W} /\left(\mathrm{m}^{2} \cdot \mathrm{K}\right)$; $\beta$-volumetric void fraction; $\lambda$ - thermal conductivity, $\mathrm{W} /(\mathrm{m} \cdot \mathrm{K}) ; v$ - kinematic viscosity, $\mathrm{m}^{2} / \mathrm{s}$.

\section{Indexes}

$f$ - value referred to foam flow;

$g$ - value referred to gas.

\section{References}

[1] Sadoc, J. F., Rivier, N., Foams and Emulsions, Nato ASI Series, 1997.

[2] Tichomirov, V., Foams. Theory and Practice of Foam Generation and Destruction, Chimija: Moscow, 1983.

[3] Gylys, J., Hydrodynamics and Heat Transfer Under the Cellular Foam Systems, Technologija: Kaunas, 1998.

[4] Fournel B., Lemonnier H., Pouvreau J., Foam Drainage Characterization by Using Impedance Methods. Proc. $3^{\text {rd }}$ Int. Symp.on Two-Phase Flow Modelling and Experimentation, p. [1-7], 2004.

[5] Gylys J., Jakubcionis M., Sinkunas S., Zdankus T., An Experimental Study of Upward and Downward Foam Flow in Small Test Bundle. Proc. $12^{\text {th }}$ International Heat Transfer Conference, Grenoble, France, pp. 399-404, 2002.

[6] Gylys, J., Jakubcionis, M., Sinkunas, S., Zdankus, T., Description of tube bundle heat transfer in foam flow. Proc. of the $4^{\text {th }}$ Baltic Heat Transfer Conference, eds. B. Sunden \& J. Vilemas, LEI: Kaunas, pp. 541-548, 2003.

[7] Gylys J., Sinkunas S. and Zdankus T., Experimental Study of Staggered Tube Bundle Heat Transfer in Foam Flow, 5th International Symposium on Multiphase Flow, Heat Mass Transfer and Energy Conversion, Xi'an, China, p.[1-6], 2005.

[8] Schenck H., Theories of Engineering Experimentation, Mir, Moscow, 1972.

[9] Zukauskas A., Convectional Heat Transfer in Heat Exchangers, Nauka: Moscow, p. 472, 1982. 